\title{
LA EQUIDAD DE GÉNERO: DE LA EVOLUCIÓN POLITICA, SOCIAL Y EDUCATIVA DE LA MUJER, HASTA LA PARTICIPACIÓN EMPRESARIAL ACTUAL
}

\author{
HELLEN RUIZ HIDALGO \\ Observatorio de Comercio Exterior \\ Vicerrectoría de Investigación \\ Universidad Estatal a Distancia, Costa Rica \\ hruiz@ocex.uned.ac.cr
}

\begin{abstract}
RESUMEN
A partir de un análisis de la evolución del estado social, político, educativo y laboral de la mujer, se ofrece una visión del tema de cuotas de mujeres en la administración de las empresas como herramienta para promover la plena competitividad de los países, más allá de la equidad, ante la persistente subrepresentación femenina en la dirección de las empresas. Después de un somero repaso de la conciencia de las contradicciones entre los principios de igualdad jurídica y la exclusión de la mujer de la vida política, se da énfasis a las motivaciones de índole económica en la participación laboral de las mujeres y se introduce el tema de las acciones afirmativas en Latinoamérica y Costa Rica. Se presenta el contraste entre los avances educativos de la mujer y su subrepresentación en puestos directivos, como contraria a toda lógica de eficiencia empresarial. Se ofrece una panorámica del debate del tema desde la óptica de mejorar la competitividad con mayor participación femenina en la dirección de las empresas.
\end{abstract}

PALABRAS CLAVE: CUOTAS, EQUIDAD DE GÉNERO, ACCIONES AFIRMATIVAS, RACIONALIDAD ECONÓMICA, BRECHAS DE GÉNERO.

\begin{abstract}
This article deals with the evolution of the social, political, educational and labor status of women before the introduction of quotas to increase female participation in the administration of enterprises as a tool to promote national competitive-
\end{abstract}

ness under the consideration of equity and motivated by the under-representation of women in senior corporate management. After a brief review of the contradictions between the principle of juridical equality and the exclusion of women from political life, emphasis is placed on the economic rationale of women's participation in the labour force, and on the discussion of affirmative action in Latin America and Costa Rica. The improvement in the education of women is contrasted with their underrepresentation in directive boards as contradictory to all logic of managerial efficiency. An overview of this debate is presented from the viewpoint of competitiveness improvement through a greater female participation at senior levels of management.

KEY WORDS: QUOTAS, GENDER EQUALITY, AFFIRMATIVE ACTION, ECONOMIC RATIONALITY, GENDER GAPS.

\section{INTRODUCCIÓN}

El tema de la participación equitativa de mujeres en todos los campos de la vida social ha sido sujeto de múltiples análisis, debates públicos, acciones de protesta, estudios, legislaciones e iniciativas diversas por parte de diferentes actores políticos, sociedad civil y academia, y se han convertido en asunto de Estado, en casi todos los países del mundo. Sin embargo, ese debate ha sido, casi siempre, planteado desde el ángulo jurídico de la igualdad de derechos o desde el social de la equidad de género. Por primera vez se comienza a promover la participación de las mujeres desde el ángulo de la competitividad. 
Desde el mismo inicio de la modernidad, cuyas fechas más emblemáticas de arranque se remontan a la Revolución Americana en 1776 y a la Revolución Francesa en 1789, las instituciones democráticas suscitadas bajo su influjo, lejos de tener como objetivo la participación universal en la vida política, estaban marcadas por una visión tan interiorizada socialmente que no necesitó excluir de forma expresa a las mujeres de la vida pública. Las denominaciones "hombre" y "ciudadano" no se introdujeron en la legislación de derechos civiles como representación de la humanidad en su conjunto, sino que específica y concretamente designaban los derechos políticos del género masculino.

Desde la suerte trágica de Olimpia de Gauges, que fue condenada a la guillotina por su lucha a favor de los derechos de las ciudadanas, la flagrante violación de los principios básicos en los que se fundaba la naciente democracia y la condición subordinada en que quedaron las mujeres en la vida pública de la naciente modernidad, fueron enfrentadas por diversos movimientos de mujeres que lograron, país por país, el reconocimiento del voto femenino, la emancipación económica y social, su admisión a las universidades, su incorporación en el ejercicio de las profesiones liberales y científicas y, solo recientemente, su participación en los organismos legislativos, de dirección administrativa y política del Estado.

Este proceso duró más de 200 años y en muchos países del mundo está lejos de haberse consolidado. Mientras tanto, los avances alcanzados de participación femenina en la vida política y económica de los países más industrializados han culminado con la práctica paridad femenina en la fuerza de trabajo y, en muchas partes, en la ya mayoritaria admisión y graduación de mujeres en las universidades. Estos avances contrastan, sin embargo, con el lugar extremadamente minoritario de las mujeres en los cuerpos de dirección política, empresarial y académica de todos los países en los que la mujer ya demuestra tener un desempeño académico, laboral y administrativo por lo menos igual al de sus contrapartes masculinas.

Se trata, como ha sido señalado en variados estudios, de la existencia de una barrera culturalmente interiorizada, que no se puede expresar en ninguna prohibición legal formal existente, pero cuya existencia socialmente patente ha sido denominada glass ceiling (techos de vidrio). Esa es la designación sugestiva que se le ha asignado a esa barrera "no escrita, pero real", es decir, invisible, con la que se pone un límite al progreso de las mujeres en la vida social (Cotter, Hermse, Ovadía y Vanneman, 2001).

Para enfrentar las brechas existentes entre los derechos legislativos nominales y su ejercicio social real, se ha impulsado, a partir del siglo pasado, legislación positiva que intenta acciones compensatorias para superar los desequilibrios existentes. Este tipo de legislación se conoce con el nombre de "acciones afirmativas". En América Latina, varios países han establecido, por ejemplo, cuerpos de ley en los que expresamente se ordena la inclusión de las mujeres, en una proporcionalidad obligatoria -en Costa Rica expresamente paritaria- en las papeletas electorales de los partidos.

La ley ha sido así utilizada como instrumento de cambio social, de enfrentamiento coactivo a los prejuicios sociales interiorizados y de mecanismo de reestructuración de relaciones de poder. Hasta ahora las acciones afirmativas se han planteado desde la perspectiva ética de la equidad.

Sin embargo, este tipo de acciones han llegado, recientemente en Europa, al terreno específico de la gerencia empresarial, donde el escaso número de mujeres en los cuerpos directivos de las empresas contrasta con la cada vez mayor presencia femenina en los niveles administrativos medios. Discrepa también con la cada vez 
mayor calificación profesional de las mujeres, así como con su probado desempeño profesional.

Siguiendo la misma lógica de las "acciones afirmativas", algunos países han promovido legislación que impone cuotas obligatorias de mujeres en los organismos de dirección de las empresas. El debate se ha extendido y forma parte de la discusión más actualizada de la vida empresarial moderna.

La lucha por una mayor presencia femenina en la administración de las empresas corresponde, por una parte, al cumplimiento de objetivos éticos de equidad, pero también enfrenta el cuestionamiento de si la promoción de las mujeres en la dirección de las empresas respeta los objetivos fundamentales de la vida económica empresarial, de mayor competitividad económica, eficiencia administrativa y libertad de mercado. Es notable que ahora, más allá del tema de la equidad, muchos autores y políticos, de orientación incluso fuertemente liberal, vislumbran desde nuevos ángulos de competitividad la importancia de la participación femenina en la administración de las empresas.

La sociedad del conocimiento y de la comunicación, así como la velocidad de transformaciones impulsadas por la continua revolución tecnológica, obligan a las empresas a tener una flexibilidad muy grande, que solo es posible en estructuras de menor rigidez jerárquica vertical. En su laureado estudio, "Mujeres y Liderazgo, una nueva forma de dirigir" Ramos (2005) hace un exhaustivo análisis en el que muestra que las mujeres tienen menor inclinación al ejercicio rígido y vertical de la administración y que estas formas propias de socialización de las mujeres ponen al día una nueva dimensión de su participación equitativa en la dirección empresarial: la eficiencia.

Los entornos empresariales sometidos a constantes cambios requieren de nuevos estilos de dirección y demandan la incorpo- ración de liderazgo transformacional en los periodos de cambio acelerado. Por tanto, las mujeres, que en general tienen un estilo con una tendencia clara al liderazgo transformacional, son candidatas ideales a ocupar puestos directivos en las organizaciones presentes y futuras. Ello no implica que los hombres no tengan el perfil adecuado para desempeñar las funciones directivas, sino que ante la situación de discriminación laboral que sufren las mujeres, reconocer que su estilo de liderazgo responde a las demandas organizacionales actuales es un argumento imprescindible para fomentar el acceso y promoción de mujeres directivas (Ramos, 2005, p.196).

\section{La larga marcha de la superación de la desigualdad política de la mujer}

El nacimiento de los tiempos modernos vino acompañado con la flagrante contradicción entre los principios políticos y jurídicos de igualdad que proclamaba y su legislación positiva concreta que excluía, de forma expresa, a la mujer de la vida pública. El primer paso para revertir históricamente esa situación fue la lucha por el pleno ejercicio de los derechos de ciudadanía de las mujeres.

Algunos pensadores, como Nicolás, marqués de Condorcet, hicieron notar tempranamente la contradicción entre los principios revolucionarios que proclamaban la igualdad básica entre los seres humanos, como "derecho natural", y que, por otra parte, negaban a las mujeres el acceso a la vida política (Calvera, 1982, p. 147). Un año antes de la redacción de los "Derechos de la mujer y la ciudadana", de Olimpia de Gouges, Condorcet abogó expresamente por la concesión de plenos derechos políticos a la mujer. En su escrito Essai sur l'admission des femmes au droit de cité (Condorcet, 1790, p. 1), reclama con claridad: "¿No han violado todos ellos el princi- 
pio de la igualdad de derechos al privar con tanta irreflexión a la mitad del género humano de concurrir a la formación de las leyes, es decir, excluyendo a las mujeres del derecho de ciudadanía?". Válido es decir que semejante postura ética de este pensador no se produjo sin la formidable influencia que ejerció sobre él su esposa, Sophie de Grouchy, fundadora y alma del círculo de intelectuales que se reunía en el "Salón de las Monedas", en pleno período revolucionario.

Pero ni las ideas de Condorcét-Grouchy, Mme d'Epinay, I'Abbé Grégoire, Pierre Guyomat, SaintJust y Cambaceres, entre otros y otras, tuvieron impacto alguno en la evolución política de Francia. Los judíos fueron ciudadanos plenos desde 1791 y la esclavitud fue abolida en 1794. Las mujeres, en cambio, tuvieron que esperar hasta 1944 para tener derecho al voto. ¡153 años!

Para entender la fuerza que tenía la interiorización cultural de la subordinación social y política de la mujer, basta con mencionar que el código napoleónico de 1804, consagra los grandes principios civiles de la Revolución Francesa, fundados en la igualdad de las personas pero, al mismo tiempo y de forma expresa, coloca a la mujer, en una situación jurídica completamente subordinada al hombre. Ahí se establece:

...subordinación de la esposa a su marido y de la obediencia a sus deseos (artículo 213). Está obligada a vivir en el domicilio que él escoge y a seguirlo donde él quiera (artículo 214). La mujer no puede disponer de su propiedad personal sin permiso del marido (artículo 217). En caso de divorcio los hijos quedan con el padre (artículo 267). Si existe adulterio, el único castigo para el marido es que le está prohibido casarse con su amante, pero si la culpable es la esposa, puede ser encarcelada por un período de dos meses a dos años (artículo 298) (Borloz, 2001, p. 62).

Las cosas no fueron diferentes en la naciente democracia de Estados Unidos. También ahí la liberación de los esclavos precedió por muchísimos años a la plena incorporación política de la mujer. Eso ocurrió, igual que en Francia, a despecho de los sentimientos de las mujeres que participaron activamente en las luchas por la independencia americana. Nada es más ilustrativo de esto - y tal vez menos conocido - que la correspondencia, entre Abigail Adams y su marido, 13 años antes de la caída de la Bastilla y dos meses antes de la proclamación de la Independencia de los Estados Unidos, en cuya redacción John Adams tomaría parte.

En el nuevo código de leyes, que supongo tendrán que redactar, desearía que te acordases de las damas, y que fueses más generoso y condescendiente con ellas que tus antepasados. No pongas un poder tan ilimitado en manos de los maridos. Recuerda que todos los hombres serían tiranos si pudieran. Si no se nos presta especial atención y cuidado a las damas, estamos decididas a organizar una rebelión y no nos consideraremos obligadas a obedecer ninguna ley en la que no hayamos tenido ni voz ni voto (Adams y Adams, 1776, p. 121).

A lo que respondió John:

En cuanto a tu extraordinario código de leyes, no puedo menos que reírme. Hemos sido informados que, a causa de la lucha, se ha relajado la autoridad en todas partes; que los niños y los aprendices desobedecen; que en las escuelas y colegios ha habido desórdenes; que los indios se han sublevado contra sus guardianes, y que hay negros que se han insolentado con sus amos. Sin embargo, tu carta ha sido la primera amenaza de que otra tribu, más numerosa y poderosa que las demás, empieza a estar descontenta (Adams y Adams, 1776, p. 125).

La contradicción era evidente, desde el punto de vista ético, entre la igualdad que se pregonaba y la discriminación de las mujeres que se prac- 
ticaba. La documentación existente demuestra que el fenómeno fue totalmente deliberado. Así, por ejemplo, nadie tan emblemático como Emmanuel Joseph Sieyès, el célebre autor del escrito más movilizador y popular de la Revolución Francesa, quien justifica la exclusión política de la mujer con base en las transformaciones económicas que precedieron a la caída del Antiguo Régimen, según la cual las fuerzas económicas remitían a la vida doméstica a las mujeres -vistas exclusivamente desde sus funciones reproductivas- y excluyéndolas de la política.

...la modernidad desarrolló la producción en toda Europa. Los sistemas políticos modernos se asientan en el trabajo, afirma Sièyes, y los agentes económicos son, efectivamente, ciudadanos activos que contribuyen a la producción social de la riqueza. Pero esa misma transformación que extrae de la economía su carácter doméstico y la hace acceder a la dimensión política, es la que mantiene las funciones reproductivas en el ámbito doméstico, excluídas de la esfera pública (Fauré, 2010, p. 187).

Exactamente lo contrario fue lo que ocurrió. Las fuerzas económicas despertadas por la Revolución Industrial arrancaron a las mujeres de la esfera doméstica, las sometieron masivamente a los más inclementes entornos laborales y crearon condiciones sociales con la fuerza necesaria para alcanzar su plena incorporación a la vida política y a la abolición de sus diferentes estatutos jurídicos de minusvalía. Esa circunstancia explica tal vez por qué fue precisamente un economista, John Stuart Mill, el escritor de mayor influencia en la defensa de los derechos políticos de las mujeres.

En 1866, John Stuart Mill planteó una propuesta en el Parlamento inglés, a favor del voto femenino que fue rápidamente rechazada, provocando el surgimiento del primer grupo claramente sufragista británico, la National Society for Woman's Suffrage (Asociación Nacional para el Sufragio de la Mujer). Su escrito de tres años después, "El Sometimiento de las mujeres", fue rápidamente traducido a todos los idiomas del norte europeo, alimentó el debate sufragista y se puede decir que precede en más de 100 años al debate actual.

El principio regulador de las actuales relaciones entre los dos sexos -la subordinación legal del uno al otro- es intrínsecamente erróneo y ahora constituye uno de los obstáculos más importantes para el progreso humano; y debiera ser sustituido por un principio de perfecta igualdad que no admitiera poder y privilegio para unos ni incapacidad para otros (Mill, 1869, p. 220).

Lo más interesante de la postura de Mill es que sitúa la plena participación de las mujeres no solo desde el punto de vista ético, sino desde la perspectiva de los aportes ventajosos que tendría en la sociedad el "carácter" específico de las mujeres, forjado, según Mill, por milenios de opresión que las prepararían para una intervención "suavizante" en la historia del género humano, si tuvieran la posibilidad de ejercer su influencia con su incorporación a la vida política pública:

La opinión de las mujeres ejercería...una influencia... más beneficiosa sobre la masa general de las creencias y los sentimientos humanos...Las mismas que eran más propensas a ser víctimas de la violencia han tendido de manera natural a hacer todo lo posible por limitar el alcance de esta y a mitigar sus excesos. Las mismas a las que no se enseñaba a luchar, han optado de manera natural por cualquier otro modo de resolver las diferencias que no fuera la lucha (Mill, 1869, p. 220).

Desde 1848, se suscitó en los Estados Unidos un movimiento de lucha por el voto de la mujer. Los esclavos fueron liberados 55 años antes que la mujer conquistara el derecho al voto, en 
ese país. El movimiento y aspiración sufragista se extendió a todos los países del mundo, pero su aceptación fue extremadamente lenta. Antes de 1914, las mujeres podían votar solo en cuatro países, geográficamente aislados, dos escandinavos (Noruega y Finlandia) y dos en la lejana Oceanía (Nueva Zelanda y Australia). En la mayor parte de los países del mundo el derecho al voto de la mujer llegó hasta después de 1946, en Costa Rica en 1949.

El derecho al voto implicó para las mujeres muchos cambios legislativos posteriores, ya que su fuerza, electoralmente adquirida, se vitalizó con la oferta política de mayores libertades civiles y sociales, que se le presentaban para seducir su poder electoral. Sin embargo, y esto nos introduce al tema de las cuotas femeninas, el hecho de poder votar no se tradujo en una mayor participación de las mujeres en los cuerpos legislativos.

\section{De la familia a la industria: la desigualdad de la mujer en la empresa}

Se suele mencionar la participación de las mujeres en la producción como uno de los factores que incidió en el crecimiento de su influencia social. Es importante, sin embargo, apartar la idea de que la revolución industrial y el maquinismo provocaron la incorporación de las mujeres en la producción por la vía de la demanda laboral. La mujer ingresó al mundo laboral de la industria moderna como un mecanismo de racionalización económica, para disminuir los costos de producción.

Ya sea en la rama textil, en la fabricación de calzado, en la sastrería o el estampado, ya sea en combinación con la mecanización, la dispersión de la producción o la racionalización de los procesos de trabajo, la introducción de las mujeres significaba que los empleadores habían decidido ahorrar costes de fuerza de trabajo (Duby, 2001, p. 427).
La racionalidad de su incorporación al trabajo asalariado de las fábricas se fundó en la posibilidad que tenía la industria de incorporar a la producción un segmento "desvalorizado" de la población humana, y de esa desvalorización social poder derivar una ventaja competitiva: conseguir igual trabajo por menor salario.

Los economistas, junto a la explicación de las leyes del desarrollo económico e industrial, construyeron también un cuerpo de razonamiento que justificaba las diferencias salariales entre las mujeres y los hombres. Uno de esos constructos peregrinos fue el concepto de "división sexual del trabajo". Según este los hombres debían recibir mayores salarios que las mujeres por su "supuesto" lugar "natural" como responsables de toda la familia, posición que no se atribuía a las mujeres.

Adam Smith, el padre del liberalismo económico, cita expresamente la opinión de economistas que el hombre debe recibir un salario que sea suficiente para mantenerse a sí mismo y a su familia, mientras que "...el trabajo de la esposa... no supone más que el que sea suficiente para mantenerse a ella misma" (Smith, 1776, p. 43).

Jean-Baptiste Say expresa el mismo criterio, como ineluctable ley económica. Según este autor, los hombres ganaban salarios esenciales, las mujeres, salarios complementarios. Ya que las mujeres podían apoyarse en el sostén familiar provisto por el trabajo de los hombres (Say, 1841).

Semejante desvalorización del trabajo de las mujeres partía, en realidad, de una preexistente cultura de subordinación de las mujeres. Sin embargo, los menores salarios de las mujeres se convirtieron a su vez en agentes económicos adicionales de su depreciación social. Por ser socialmente desvalorizada recibía menor salario y, a su vez, ese menor salario que recibía, era "la prueba" de su condición desvalorizada. "Por un lado, los salarios de las mujeres daban por supuesto la menor productividad de estas; 
por otro lado, los bajos salarios de las mujeres se consideraban como demostración de que no podían trabajar tanto como los hombres" (Scott, 2001, p. 8).

A pesar de todos los avances sociales y jurídicos que han existido, desde la primera revolución industrial, en ningún terreno ha habido tanta lentitud y tan difícil progreso como en conseguir que las mujeres reciban la misma remuneración por igual trabajo. En 2009, un análisis de 22 países mostró que en promedio, "la brecha salarial de género se ha mantenido invariable; en el periodo analizado, las mujeres ganan aproximadamente el $80 \%$ del salario de los hombres" (OIT, 2009, p. 8). En la misma medida en que los niveles de empleo de las mujeres son de mayor calificación profesional, la brecha salarial entre hombres y mujeres, en vez de acortarse, se expande (OIT, 2009). Por otra parte, si se toma en cuenta los niveles salariales de participación femenina en todas las escalas salariales, siempre es mayor el número de mujeres que de hombres que gana menos del promedio nacional. En los Estados Unidos, por ejemplo, donde se ha alcanzado prácticamente la paridad en participación laboral entre hombres y mujeres, y donde además la tasa de desempleo de mujeres es menor que las de sus contrapartes varones, "En 2008, casi el 30\% de las mujeres que trabajaban a tiempo completo ganaban menos de dos tercios del salario medio, frente a solo el $20 \%$ de los hombres" (OIT, 2009, p. 9). En otras palabras, una de cada tres mujeres asalariadas gana menos del $60 \%$ del salario nacional medio.

\section{Las acciones afirmativas como mecanismos compensatorios}

La igualdad jurídica, institucionalmente establecida, no ha impedido que la realidad presente un tratamiento diferenciado en el acceso a oportunidades entre hombres y mujeres, entre diferentes etnias, credos y orientaciones sexuales. Ante esas contradicciones entre los estatutos jurídi- cos que consagran formalmente la igualdad y la real desigualdad social y económica que se presenta con evidencia empírica, se han venido implementando medidas socialmente correctivas, convertidas en imperativas por estatutos internos o por legislación nacional, en la forma de cuotas obligatorias de participación, de acceso a oportunidades, de empleo, entre otros. Marta Suplicy, ex intendente de Sao Pablo, las define así:

Acciones afirmativas son estrategias destinadas a establecer la igualdad de oportunidades, por medio de medidas que compensen o corrijan las discriminaciones resultantes de prácticas o sistemas sociales. Tienen carácter temporal, están justificadas por la existencia de la discriminación secular contra grupos de personas y resultan de la voluntad política de superarla (Suplecy, 1996, p. 131).

El concepto apareció, por primera vez en legislación introducida por el presidente John F. Kennedy, en la orden ejecutiva número 10925 del 6 de marzo de 1961, donde se plantea la contradicción social existente entre los principios constitucionales de igualdad y los resultados que aportan "los exámenes y análisis de prácticas... relacionadas con el empleo que muestran la urgente necesidad de fortalecer la promoción de la total igualdad de oportunidades de empleo" (Kennedy, 1961).

En esta orden ejecutiva, se emplea por primera vez el término "acción afirmativa" y se refiere específicamente, en su sección 301-1, a la obligación que tienen los contratistas del gobierno de los Estados Unidos a "tomar medidas afirmativas (affirmative actions) para asegurar que los aplicantes a un empleo sean contratados y tratados sin discriminación por razón de su raza, credo, color u origen nacional" (Kennedy, 301-1).

Debe tomarse en cuenta que en esta disposición no incluye, ni considera la discriminación 
por razón de género (without regard to their race, creed, color, or national origin). Luego vendrá en ese país una emblemática legislación relacionada con los Derechos Civiles, en ella las mujeres no son mencionadas. En 1965 el presidente norteamericano Lyndon B. Johnson emitió la orden ejecutiva 11246 en la que extiende a las empresas privadas de más de 15 empleados los beneficios de no discriminación en el empleo. Aún entonces no se menciona a las mujeres y no es sino hasta 1967, que se reforma esa orden ejecutiva, para que abarque también a las mujeres.

Esa es, entonces, la primera vez que las acciones afirmativas jurídicas van a relacionarse con la tutela de la igualdad de género. El concepto de cuotas específicas, como forma de promoción de la igualdad nace mucho después, pero solo como instituciones de derecho privado, dentro de los estatutos de las universidades en Estados Unidos o de los estatutos de los partidos políticos en Escandinavia.

Los primeros antecedentes de acciones afirmativas debemos retraerlas a los estatutos de 1890 del Partido Socialdemócrata de Alemania (SPD) que expresamente demandó una mayor representación de las mujeres afiliadas en las convenciones de ese partido. Eso no hizo, sin embargo, variar el porcentaje de mujeres que se presentaban como candidatas. Clara Zetkin, directora del periódico "La Igualdad" y a quien se debe la propuesta de celebración del día internacional de la mujer, fue diputada hasta 1919, junto a otras 37 mujeres alemanas (9\%). Un año después de finalizada la Segunda Guerra Mundial, el SPD resolvió que en todos los cargos partidarios debía existir una representación de mujeres proporcional a la membresía femenina. Eso marca la tendencia europea moderna (Barbieri, 2002), en la cual la introducción de cuotas específicas de mujeres van a ser producto de estatutos internos de los partidos y no de legislación electoral nacional.
Este nuevo proceso arranca en 1976, en Noruega, cuando después de un fuerte debate interno, las mujeres afiliadas al partido socialdemócrata lograron convencer a la mayoría masculina de ese partido a presentar cuotas específicas de candidaturas femeninas en las listas de candidaturas al legislativo. Ese ejemplo y las nuevas diputadas abrieron la puerta a intensos debates que condujeron a que, poco a poco, todos los partidos asumieran de forma voluntaria un compromiso similar con la representación femenina en las papeletas electorales, tendencia que rápidamente se extendió a todos los países escandinavos.

Las nuevas disposiciones partidarias van a tener un fuerte impacto en el crecimiento de la participación de mujeres en los parlamentos y en los gobiernos europeos. Una tendencia similar, pero esta vez a través de legislación, establecería en América Latina cuotas de mujeres en las candidaturas al legislativo a partir de 1991.

\section{Estado de situación de las cuotas de mujeres en política electoral}

En la Europa de mayor tradición democrática ha existido una enorme resistencia a la legislación obligatoria de cuotas de mujeres en las papeletas electorales y solamente ocho países han establecido esa obligación. Sin embargo, el establecimiento de cuotas femeninas es vista, cada vez más, como la política de estado más eficaz en la promoción de la igualdad de representación de mujeres en el legislativo y en todas las esferas de gobiernos, nacionales y locales (Dahlerup, 2005).

De hecho, en la zona escandinava nunca se establecieron cuotas por ley, lo que es contrario a lo que habitualmente se supone. Sin embargo, ha sido emblemática su alta participación de mujeres en el Legislativo, lo que demuestra el peso de otros factores culturales, sociales y económicos en la promoción de la participación de 
mujeres en los parlamentos. En algunos de esos países, ni siquiera los partidos pusieron cuotas en sus estatutos. En otros, como en Dinamarca, segundo en proporción de mujeres en el parlamento, pocos partidos establecieron cuotas en sus papeletas electorales y, si lo hicieron, las han eliminado recientemente.

Una situación completamente diferente es la que se ha vivido en América Latina. Aquí la tendencia predominante ha sido buscar incidir en la mayor representación de mujeres en los parlamentos a través de la imposición de cuotas obligatorias de mujeres en las listas electorales.

En los años 90 del siglo pasado, la región latinoamericana vivió un profundo proceso de democratización de la vida política en la que asumieron particular relevancia organizaciones de mujeres, como las abuelas de la Plaza de Mayo, en Argentina. En ese contexto, también se promovió la participación de las mujeres en las nuevas instituciones democráticas de la región. Una de las medidas consideradas por la población como las más positivas para asegurar la representación parlamentaria femenina fue el establecimiento de cuotas como mecanismo que "tiene un objetivo equilibrador de las desigualdades que enfrentan las mujeres para acceder a cargos políticos, al forzar su ingreso al poder público y no dejarlo completamente a la buena fe de los partidos políticos, ni a sus procedimientos tradicionales de selección"(Peschard, 2002, p. 174).

Argentina fue el primer país que adoptó el sistema de cuotas electorales en 1991. A la fecha existen 11 países que se han sumado a la iniciativa de establecer porcentajes obligatorios de mujeres en las candidaturas parlamentarias, y van desde el 20\% en Paraguay hasta el 50\% en Costa Rica y Ecuador. En Colombia existe además la obligación de poner un 30\% de mujeres en los máximos niveles de la administración pública.
Desde una encuesta Gallup, realizada en 2000, el $66 \%$ de los latinoamericanos piensan que las cuotas de mujeres son mecanismos apropiados para favorecer la incorporación de mujeres a puestos políticos. El 55\% apoyan la idea de la mayor participación de mujeres porque el 66\% opina que son más honestas que los hombres y el 85\% que son mejores a la hora de tomar decisiones (Diálogo Inter-Americano/Gallup, 2000).

En algunos países, como Costa Rica, la introducción de las cuotas parecería indicar resultados netamente positivos en el cambio de la cultura política nacional, pasando de 19,3\% de mujeres legisladoras en 2000, al 40\% después de establecido el sistema de cuotas. En nuestro país la participación de mujeres es similar a la de los países escandinavos. Un resultado igualmente exitoso se manifiesta en Argentina. En otros países los resultados son variados y mucho depende de si, además de las cuotas establecidas, se impone un orden obligatorio de las candidaturas femeninas y se establecen sanciones -como el rechazo de la inscripción de candidaturas, cuando no se cumple con la norma. Si se compara el promedio de representación de mujeres legisladoras entre países latinoamericanos que tienen cuotas $(20,5 \%)$ y los que no las tienen $(18,5 \%)$ la diferencia no es tan decisiva.

Tal vez eso se deba, como opina Jacqueline Peschard, a que:

... si no existe una disposición expresa para la colocación de las candidaturas femeninas, el objetivo de las cuotas tiende a diluirse al dejarse en manos ya sea de las cúpulas partidistas que generalmente están compuestas dominantemente por varones, ya de la población votante que participa de los valores y consideraciones dominantes sobre los quehaceres políticos, lo cual deja en desventaja a las mujeres (Peschard, 2002, p. 179).

Por otra parte, en el empoderamiento de mujeres cabe tomar en cuenta la bajísima repre- 
sentación que tienen en los gobiernos locales, donde "en 14 países latinoamericanos el número de mujeres alcaldesas está por debajo del 10\%" (Llanos y Sample, 2008, p. 11).

Eso muestra que la introducción de cuotas no necesariamente tiene un impacto que se extienda de inmediato en todos los órdenes del empoderamiento político y que en los resultados de representación femenina siguen jugando también otros factores que tienen que ver con el desarrollo cultural, nivel educativo, peso social de la clase media, influencias religiosas $y$, por supuesto, el peso específico que alcancen en los partidos políticos, la democracia interna y el accionar específico de las mujeres.

La discusión sobre el tema de las cuotas, comparando América Latina y Europa, gira el sentido de la balanza cuando se introduce el tema de la representación de mujeres en el nivel de dirección de las empresas. En este campo, se ha abierto una discusión sobre la necesidad de introducir un sistema de cuotas de participación de mujeres en puestos directivos. En Latinoamérica, en cambio, esa discusión todavía no tiene impactos notables.

\section{Los avances educativos de las mujeres tocan su techo de vidrio}

Universalmente reconocida como base de la creación de capacidades y de competitividad nacional, la educación es el instrumento más importante de movilidad social y el acervo humano de un país termina en última instancia determinado por los niveles educativos alcanzados por su población.

Contemporánea de la Revolución Francesa, la primera gran precursora inglesa de la lucha por la igualdad de las mujeres, Mary Wollstonecraft, plantea que la educación - no la política - es el mejor instrumento para la igualdad entre los sexos. En su libro "Reivindicación de los Dere- chos de la Mujer", considerado precursor del feminismo anglosajón, es del criterio que la diferencia en educación está en la base de todos los prejuicios en contra de las mujeres. El fundamental objetivo de la educación de mujeres sería lograr que la mujer, al ser "igual" al hombre en sus capacidades intelectuales y laborales, podría ser también "igual" en su posicionamiento social.

La humanidad debiera educarse siguiendo el mismo modelo, o si no, la relación entre los sexos nunca merecerá el nombre de compañerismo, ni las mujeres desempeñarán los deberes peculiares de su sexo hasta que no se conviertan en ciudadanas ilustradas, libres y capaces de ganar su propia subsistencia, e independientes de los hombres (...) hasta que las mujeres, educándose junto con los hombres, no estén preparadas para ser sus compañeras, en lugar de ser únicamente sus amantes (Wollstonecraft, 1792, p. 177).

Ese sueño de Wollstonecraft no solo es ya una realidad en casi todos los países del mundo, sino que en la mayor parte de ellos el número de mujeres en los centros de enseñanza es superior al de los hombres. Eso no ha significado, sin embargo, igualdad de las mujeres en la sociedad y en la fuerza de trabajo.

De acuerdo con el "Reporte Global de Brechas de Género 2009" (Hausmann, Tyson y Zahidi, 2009), publicado por el Foro Económico Mundial, en 83 de 132 países se había alcanzado el mismo o mayor número de mujeres en la educación secundaria. En 76 de esos 83 países, el número de mujeres en secundaria era mayor que el de los hombres. En 30 de los 49 países del mundo donde es menor el número de mujeres en secundaria, la matrícula de mujeres es igual o mayor al 90\%. Costa Rica se sitúa entre los 22 países del mundo con mayor presencia femenina en secundaria, con el $7 \%$ más de mujeres que de hombres, en ese nivel educativo (Figura 1). 
FIGURA 1

\section{Brechas entre hombres y mujeres en educación, salud, oportunidades económicas y empoderamiento político}

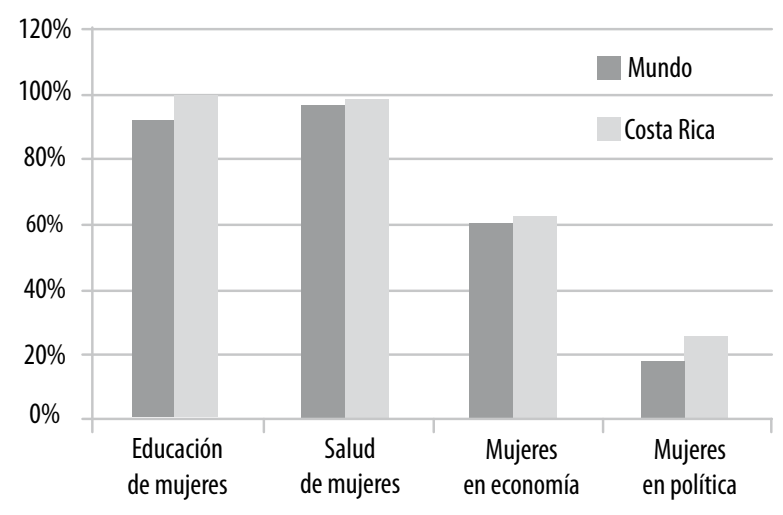

Fuente: Elaboración propia a partir del The Global Gender Gap Report (2009).

En la educación universitaria el panorama es todavía más acentuado: En 90 de 134 países se alcanza igualdad o superioridad del número de mujeres en las universidades. De ahí que el promedio mundial de participación de mujeres en educación superior es un 19\% mayor a la participación de hombres (en Costa Rica inclusive un 26\% más).

El volumen participativo de las mujeres como profesionales y técnicas en la fuerza de trabajo mundial corresponde, como era de esperar, con su cada vez mayor participación en los sistemas educativos. Por cada 10 hombres técnicos y profesionales existe una contraparte de 7,4 mujeres. Sin embargo, esa participación técnica se contrasta violentamente con su participación en las escalas superiores de dirección de las empresas, donde menos de 3 mujeres forman parte de directivas, frente a cada 10 gerentes o directores hombres. A pesar de su cada vez mayor capacidad educativa, la falta de participación femenina en niveles de empresa donde se deciden las políticas corporativas termina incidiendo en la menor valoración salarial del trabajo de las mujeres. El promedio mundial de ingresos de las mujeres es globalmente el 52\% del de los hombres y considerando los salarios percibidos por exactamente el mismo trabajo, las mujeres ganan solo el $66 \%$ de lo que ganan los hombres. Todas las leyes laborales internacionales no han podido impedir este resultado empírico que arrojan las estadísticas.

Costa Rica, país que se sitúa bastante alto en los índices de desarrollo humano, como es de esperar, tiene una excelente tasa de participación de mujeres en sus sistemas educativos y en la participación de profesionales y técnicos en la fuerza de trabajo, donde hay 12,3 mujeres por cada 10 hombres con enseñanza superior o técnica en la fuerza de trabajo. Sin embargo, cuando se consideran las diferencias de salario por el mismo empleo, el nivel de ingresos de las mujeres de Costa Rica está ligeramente por debajo del promedio internacional ya que las mujeres ganan un promedio del $65 \%$ de lo que ganan los hombres, frente a un $66 \%$, en el mundo. El nivel de influencia femenina en Costa Rica se sitúa, en cambio, un poco mejor que el promedio internacional (37\% del nivel de influencia de los hombres contra $30 \%$ en el mundo), pero eso es solo porque en esta categoría han sido tomadas en consideración la mujeres legisladoras y directivas de empresas públicas, donde Costa Rica tiene excelente desempeño. Eso señala que la situación de las mujeres propiamente en la dirección de las empresas debe estar también por debajo del promedio internacional, como lo están sus niveles salariales (Hausmann, 2009).

El contraste existente entre el avance educativo de la mujer y las persistentes brechas en las oportunidades de avance económico demuestra que fue mucho más fácil el reclutamiento de mujeres a los sistemas educativos que el impacto que esta participación está teniendo en conseguir igualdad de oportunidades profesionales y de ingresos para las mujeres. Tanto más impactante es esta desigualdad cuando se aprecia que la diferencia de ingresos se incrementa en razón directa del nivel de responsabilidad 
ocupado por las mujeres, cuando se le compara con los ingresos de los hombres en ese mismo nivel (OIT, 2009). De ahí que haya surgido el debate internacional que se cuestiona sobre la conveniencia de utilizar legislación positiva para promover la incorporación de las mujeres en la dirección de las empresas, por la vía obligatoria.

\section{Cuotas de mujeres en la administración de empresas: la discusión europea}

El tema de la igualdad de la mujer ha saltado modernamente de una discusión formal de derechos humanos hacia una visión económica de competitividad y eficiencia. El contraste patente entre los avances en la capacidad educativa y profesional de las mujeres y su desigual participación en los niveles superiores de la administración de las empresas, plantea el tema del avance social y económico de las mujeres como un tema de aprovechamiento competitivo de sus capacidades, más allá de la superación de contrastes entre la igualdad jurídica formal y la verificable desigualdad real de oportunidades.

Las expectativas de alcanzar avances con el asentamiento de la cultura democrática y con el avance educativo de la mujer parecen no haber tenido mucho impacto. Las capacidades derivadas de su mayor competencia educativa no han sido suficientes para lograr avances correspondientes a su mayor desempeño. Pero ahora existe demostración empírica que ofrece nuevos parámetros. Esa nueva evidencia está determinada por las ventajas comparativas demostradas de las pocas mujeres administradoras que han escalado los máximos niveles de administración de empresas transnacionales o de punta tecnológica. Aun así, esa evidencia de competitividad en el mercado laboral tampoco ha tenido impacto en variar el escaso número de mujeres en puestos de dirección empresarial.

Todo apunta a la continuidad de una condición socio-cultural tan profundamente arraigada que llega hasta la irracionalidad perversa de dañar poderosamente los intereses de los mismos segmentos que discriminan a las mujeres: ni la mayor oferta numérica, la mejor capacitación técnica y el menor precio de mercado de las mujeres conduce a su instalación en centros de poder económico.

Esta situación de "perversa ceguera" que no ha sido posible superar ni por la mayor educación y demostrada capacidad de las mujeres, ni por la propia conveniencia económica empresarial, ni por la necesidad de superar la competitividad nacional, encuentra en las encuestas de opinión un contraste marcado: tanto hombres (93\%) como mujeres (95\%) consideran que las mujeres están igual o mejor (10\% mujeres, 5\% hombres) capacitadas que los hombres para ocupar puestos de dirección en las empresas (Beyer y Voigt, 2011). ¿Qué pasa entonces? ¿Por qué el contraste discriminatorio si hasta las opiniones sociales de los hombres aconsejan un mayor posicionamiento de las mujeres en la dirección de las empresas?

Ese nudo gordiano, en vez de desatarlo con cuidado, se está llegando en algunos países a la decisión simplemente de romperlo, estableciendo un sistema legal de cuotas obligatorias de participación de mujeres en la dirección de las empresas.

El modelo sobre el que se ha fundado esta política se estableció en Noruega, donde una ley aprobada en 2003 ordenó que, en un plazo de 5 años, todas las compañías enlistadas en la bolsa de valores de Noruega tuvieran al menos un $40 \%$ de mujeres en sus directorios ejecutivos, bajo amenaza de ser cerradas si no lo hacían y de invalidar todas las iniciativas de las juntas directivas que no tuvieran la composición de mujeres ordenada por la ley.

Desde la entrada en efecto de esta ley, los resultados en Noruega han sido formidables. El primero de enero de 2008, cuando la ley entró en pleno efecto, todas las compañías tenían muje- 
res en sus directorios. Un reportaje de la BBC de Londres, publicado el 11 de enero de ese año, informaba que las empresas de Noruega tenían ya, en ese momento, cerca del 38\% de mujeres en sus directorios (Holmes, 2008). Con eso se colocaba delante de otros países escandinavos, siendo Suecia la que le seguía con el 20\%. Ya eso está bastante por delante de la media europea, que es solo del 8,5\%, según la Red de Mujeres Profesionales de Europa, y mucho más que en países como Italia que tienen apenas el $2 \%$ de mujeres en los directorios de las empresas (Visser y Gigante, 2007).

No debe olvidarse, sin embargo, que en Noruega pasaron muchos años en los que las cifras mostraban la creciente capacitación de mujeres profesionales con resultados nulos en la promoción de mujeres en los niveles superiores de las empresas. Los gremios empresariales dedicaban cursos especializados en la formación de líderes femeninas, capacitación de administradoras y promoción de especialistas mujeres en las empresas. Sin embargo, eso se reveló insuficiente y ante el inmovilismo se pasó a la ley, que, curiosamente, tuvo un impacto cultural notable. El número de mujeres en los consejos de administración pasó de 200 a 1000. Incluso en las empresas que no cotizan en la bolsa -y que, por tanto, no están obligadas a cuotas- el número de mujeres en su dirección ha aumentado hasta casi un 30\% en todos los mandos.

Sin embargo, la imposición por vía legislativa de un número tan alto de mujeres en la dirección de las empresas no venía sin altos riesgos de rebote negativo, si la alta cuota de mujeres en los directorios, impuesta por ley, repercutía con disminución competitiva en las empresas. De ahí que era interés de todas las partes involucradas, organizaciones de mujeres y organizaciones empresariales, asegurarse que la participación que ordenaba correspondiera con la idoneidad de las mujeres en los cargos al que serían obligatoriamente promovidas.
La Confederación de Empresas Noruegas creó acciones de entrenamiento específico de liderazgo de mujeres. La Iniciativa por un Futuro Femenino, mundialmente conocida como "pesca de perlas", consistió en la búsqueda y selección de las mujeres mejor calificadas, a quienes, después de un rigoroso filtro, recibían un entrenamiento especial de año y medio con los mejores programas mundiales de dirección de empresas y con seminarios de construcción de redes de mujeres empresarias, para crear una base social de sustento y apoyo mutuo. El resultado fue enormemente exitoso.

La realidad contradijo a quienes habían advertido que esa ley provocaría huída de capitales de Noruega. Todo lo contrario fue lo que ocurrió: la imposición de las cuotas atrajo más firmas extranjeras a inscribirse a la bolsa noruega.

Siguiendo el ejemplo noruego, Francia y España establecieron un sistema de cuotas de mujeres en la administración de las empresas que prevé que para 2017 (Francia) o 2015 (España) deberá existir un 40\% de participación femenina en los altos mandos corporativos. En los Países Bajos, está en discusión una ley semejante de cuotas que podría exigir una participación del 30\% de mujeres en los consejos de dirección. Adicionalmente, la comisión de la Unión Europea amenaza que impondría una cuota obligatoria para toda la Unión si antes de 2012 no se verifican cambios en la presencia femenina en las direcciones de las empresas. Viviane Reding, Comisaria de Justicia de la Unión Europea, expresa que:

Si hasta el final de 2011 la economía no hace ningún avance concreto, debemos plantearnos pasos legislativos en el nivel de la Unión Europea, como los que se han seguido en España, Francia y Noruega. A mi me gustaría lograr que en el año 2015 tengamos el 20\% de mujeres en puestos de dirección de las empresas inscritas en las bolsas del mercado europeo, y que en 2020 sean el 40\% (Beyer, 2011). 


\section{Más mujeres en la dirección de las empresas resulta en mayor competitividad}

Tanto en Noruega como en los demás países europeos donde se ha legislado o se encuentra en debate la legislación de cuotas de mujeres en la dirección de las empresas, la fuerza motora ha surgido de resultados empíricos de investigación de competitividad: "el instituto norteamericano Catalyst ha demostrado con un exhaustivo estudio internacional que aquellas empresas en las que existen especialmente muchas mujeres con asiento en sus juntas directivas han llegado a tener un rendimiento de capital de hasta el 53\%" (Beyer, 2011, p. 53). En tiempos de crisis económica internacional, se ha confirmado el mejor desempeño de las empresas con presencia de mujeres en sus cuerpos directivos.

Y que no se piense que nosotras demostramos eficiencia solo en temas de sensibilidad. Nada de eso. Empresas de punta tecnológica como Areva (energía nuclear), AngloAmerican (minería), Archer Daniels Midland (agroindustria), DuPont (químicos), Sunoco (petróleo) and Xerox (tecnología) han conocido las ventajas de tener gerentes femeninas (Govaere, 2011).

El propio estudio de Catalyst nos presenta los avances y las limitaciones de la situación de las mujeres en las empresas de los Estados Unidos.

Actualmente, las graduaciones de mujeres como bachiller universitario y de master son más de la mitad (57,3 y 58,5\% respectivamente) y se otorgan a mujeres casi la mitad de todos los doctorados en diferentes campos y también los títulos en leyes (49,9\% y 47,3\% respectivamente). Ya la mitad de la fuerza laboral de los Estados Unidos es formada por mujeres y su presencia en mandos medios administrativos es cada vez mayor y representa ya el 45,9\%, de acuerdo con el censo laboral de 2002 de los Estados Unidos y reportado por Catalyst en su estudio. Catalyst hizo una evaluación de las mujeres miembros de directorios y puestos de mayor remuneración, en empresas de la clasificación "Fortune 500" y notó que son mujeres solo el $15.7 \%$ de sus más altos rangos, en 2002 (Catalyst, 2004). Sin embargo, en los mandos medios, tales como jefes de departamento, son mujeres el 38\% (Gender Gap Report, 2009). Los techos de vidrio en plena función.

Una comparación del desempeño en 393 empresas del Fortune 500 de esos años mostró que:

El grupo de compañías con la mayor representación de mujeres en sus rangos superiores experimentó un desempeño superior que el grupo de compañías con el menor número de representación femenina en esos niveles de dirección. Este resultado fue consistente tanto en términos de rendimiento de capital, que fue 35,1\% mayor, como de ganancias distribuidas a los accionistas, que fue $43 \%$ mayor.

El desempeño financiero fue analizado también por rama de industria y, en cada una de las cinco industrias analizadas por separado, el grupo de compañías con la mayor representación de mujeres en los máximos equipos de dirección experimentó un mayor rendimiento de capital que los grupos de empresas con la menor representación de mujeres en sus rangos de dirección.

En cuatro de las cinco ramas industriales analizadas, el grupo de compañías que tenían mayor número de mujeres en sus puestos de dirección experimentaron una mayor distribución de ganancias a los accionistas (Catalyst, 2004, p. 2).

¿Qué ha pasado en las empresas noruegas, después de la ley desde el punto de vista de competitividad? Según Marit Hoel, presidenta del Centro Noruego por la Diversidad en las Corporaciones: 
Noruega tiene muchas mujeres en directivas de empresas y desde el punto de vista del tipo preciso de sus capacidades profesionales y de sus habilidades empresariales, así como del entrenamiento que muchas han tenido previamente en el sector público, se puede decir que su participación ha mejorado el estatus de calidad de las directivas de las empresas (Holmes, 2008, p.1).

El debate internacional está abierto y su escenario más representativo hoy es Alemania, donde el tema por primera vez atraviesa todos los partidos y todas las ideologías. A todas luces la promoción de la igualdad de la mujer está teniendo lugar en estos tiempos, rompiendo los techos de vidrio. Es la última frontera de la igualdad.

\section{El debate alemán preconfigura la discusión internacional}

Hace 10 años, Christine Bergmann, ministra de familia del Partido Socialdemócrata, de origen de Alemania del Este, propuso una ley que obligaría a la representación paritaria de las mujeres en los consejos directivos de las corporaciones. Para impedir esa ley, las empresas alemanas convinieron en suscribir un "acuerdo voluntario", de promoción de las mujeres en puestos de dirección de las empresas de forma sostenida y constantemente creciente. Diez años después, esa fórmula voluntaria no tiene prácticamente ningún resultado. Efectivamente, el 17 de Enero de 2011, el Instituto de Investigación Económica de Alemania (DIW) publicó datos sobre la participación de mujeres en la dirección de las empresas. "Los cambios son prácticamente "homeopáticos" - dijo Elke Holst del DIW (Instituto Alemán de Investigaciones Económicas).

Solo el 3,2\% de los puestos de dirección son ocupados por mujeres, si se toma como referencia las 200 firmas más importantes de Alemania. La participación de las mujeres es todavía menor, el 2,2\%, si se toma otra base comparativa, tal vez más representativa, -las 30 empresas del consorcio de la bolsa alemana (DAX) y las 100 empresas más grandes-. 0 se podría expresar más claramente diciendo que de 490 personas miembros de juntas directivas, en estas empresas, solamente 11 son mujeres (Beyerl, 2011, p. 58).

Esos resultados prueban que tampoco un acuerdo voluntario de las empresas tiene los impactos debidos. En Alemania, esto es tanto más grave cuanto que las investigaciones socio-económicas apuntan, desde ahora, a un creciente faltante de profesionales y técnicos de alto nivel que demanda la economía alemana. Según la empresa consultora McKinsey, de ahora al año 2020, si se tiene un crecimiento anual del 1,7\%, el déficit de profesionales y técnicos ya existente irá creciendo hasta alcanzar un faltante de 2,5 millones de oferentes competitivos. Si el crecimiento es de 3\% el faltante llegará a 6,1 millones de oferentes (McKinsey \& Co., 2008). Para cubrir ese faltante no será suficiente importar especialistas y será absolutamente necesario promover la participación de la fuerza de profesionales que ha sido, hasta ahora, dejada de lado: las mujeres. En Alemania, la promoción de mujeres ya es una "razón de estado".

Fue tal vez prematuro, en el verano de 2010, el intento de Christine Bergmann, ministra socialdemócrata de asuntos de mujer y familia, durante el primer gobierno de Gerhard Schröder, de impulsar una ley de cuotas de representación de mujeres en los consejos de empresa. Desde entonces, sin embargo, mucha agua ha corrido por los ríos de la política europea y de la vida de las empresas alemanas.

El "experimento noruego" con las cuotas ofrece un ejemplo exitoso. De hecho, una particularidad del caso noruego se puede repetir ahora: fue ahí un gobierno de "derecha conservadora" el que introdujo las cuotas, apoderándose así de una consigna tradicional de la "izquierda". ¿Por qué no introducir entonces en Alemania el 
sistema de cuotas con un gobierno de derecha como el de Angela Merkel, pero que no solo está dirigido por una mujer, sino que tiene además el $30 \%$ de mujeres en su gabinete?

Es quizás con esa visión que la ministra del trabajo Ursula von der Leyen avanzó, en 2010, la propuesta de alcanzar por ley, en 5 años, una cuota del 40\% de mujeres en los consejos de dirección de las firmas inscritas en la bolsa alemana. Su propuesta se enfrentó a la oposición de Kristina Schröder, ministra de mujer y familia de su propio partido, quien siguió defendiendo la vieja tesis de dejar que las empresas decidan voluntariamente aumentar el número de mujeres en sus directivas. En medio del contrastante debate entre las dos ministras del mismo partido, la jefa de gobierno, Canciller Angela Merkel, zanjó provisionalmente la discusión, pronunciándose en contra de las cuotas.

El caso alemán muestra cómo en esta discusión se cortan las líneas ideológicas. Los socialdemócratas, con minoría en el parlamento, ya presentaron una propuesta de ley de cuotas, apoyada también por los Verdes. Pero en el debate entre las tres mujeres ministras intervino a favor de las cuotas una cuarta mujer, también ministra, esta vez desde la extrema liberal más recalcitrante, el FDP (Partido Libre Alemán), en abierta oposición con la línea de su partido. Sabine LeutheusserSchnarrenberger, Ministra de Justicia, se pronunció como defensora de un código de gobernabilidad corporativa, que debería incluir la obligación de representación de mujeres en los consejos de gestión.

Las mujeres no se van a seguir dejando manipular. Los empresarios deben entender que si nada cambia en la composición de la dirección de las empresas, sobre sus cabezas cuelga desde ahora la espada de Damocles de una cuota de mujeres impuesta por ley (Seith, 2010, p.1).
Ilse Eigner, otra ministra del gobierno de Merkel, esta vez de agricultura, opositora tradicional de las cuotas, no tiene dudas en participar ahora, ella también, a favor de un cambio por la vía legal:

Por convicciones personales profundas me he opuesto desde hace mucho tiempo a cualquier forma de cuotas. Pero, después de mucha experiencia, me he llegado a convencer que los llamados a la buena voluntad no logran nada y que voluntariamente las empresas no hacen nada (Fischer, 2011, p.1).

La idea gana momento también en las empresas alemanas. El expresidente de la BDI (cámara de industria alemana) Hans-Olaf Henkel se pronunció a favor de las cuotas y recientemente, la compañía Telecom se puso el objetivo de una cuota voluntaria del $30 \%$ de mujeres en posiciones de dirección a cumplir en 5 años. Otras empresas importantes tales como el gigante de energía E.ON anunció, en febrero de 2011, que llevará la participación de las mujeres al 22\% de inmediato, sin ponerse plazo. Por su parte, BMW y Daimler Benz decidieron elevar hasta el 20\% de mujeres en 2020 y la compañía Bosch dijo que en un año más tendrá al menos 15\% de mujeres en sus mandos (Michles, 2011).

El volumen de esa fuerza femenina mayormente desperdiciada es enorme. Desde hace ya más de 10 años se mantiene en Alemania una consolidada tendencia a que las mejores mujeres tengan las mayores promociones de conclusión de colegios de secundaria y de universidades. También conservan mayoría absoluta en las graduaciones: el 51\% de títulos universitarios son ganados por mujeres. Su porcentaje llega hasta el $60 \%$ en los títulos universitarios de administración de empresas.

Sin embargo, el tema de la mayor participación de mujeres no está totalmente excluido del menor pago que ellas reciben dada su menor valoración social, pero también de las condiciones laborales que se ven obligadas a aceptar dadas 
sus condiciones familiares como madres. Muchas empresas han optado por gerencias femeninas por que son más baratas. Un tema tan viejo como el capitalismo. Pero eso también tiene que ver con competitividad.

El periódico "Tageszeitung (TAZ)" de inclinación de izquierda, es uno de los mejores de Alemania e introdujo voluntariamente un sistema de cuotas de mujeres en su dirección desde hace 30 años. Desde entonces ha tenido directoras mujeres con bastante frecuencia y es actualmente también dirigido por una mujer. Sin embargo, comparado con otros medios de difusión, son conocidos los menores salarios que ofrece a su personal y eso los ha obligado a adaptarse a las condiciones de las mujeres ofreciéndoles un trabajo menos remunerado. El TAZ contaba con menor capacidad financiera y al flexibilizar sus condiciones de trabajo e incorporar mujeres redactoras de calidad, pudo aprovechar para tener personal de primera, por un menor costo. De hecho, con esas condiciones laborales y en esos puestos no había oferta laboral para mujeres en la industria de publicaciones. Bascka Mika, directora del "TAZ" por 10 años explica:

Como nosotros no podíamos pagar mucho dinero, tuvimos que buscar cómo entusiasmar a la gente que estaba dispuesta a mantenerse entre nosotros... Se puede decir también que la falta de medios económicos ha obligado al "TAZ" a permitir en su seno desarrollar estructuras avanzadas: tiempos flexibles de trabajo, tiempo para cuidado de hijos, teletrabajo, etc., y eso ha probado que esta política no necesariamente condena a una empresa al fracaso, sino todo lo contrario (Beyer, 2011, p. 62).

El debate alemán también muestra el tema de las cuotas de mujeres como un debate cultural que se introduce incluso en el seno de las mismas defensoras de las cuotas, como un proceso que enfrentará a muchas mujeres con condiciones sociales de mayor responsabilidad que no siempre son aceptadas por todas las mujeres. De hecho, sería absurdo pensar que los prejuicios sociales no calan también en el seno de quienes son objeto de las discriminaciones en la forma de una visión socialmente disminuida de sí mismas.

Uno de los libros que más impacto tendrá, por la radicalidad de sus planteamientos, es precisamente el recientemente aparecido "La cobardía de las mujeres", de la vieja directora del TAZ. Ella plantea que:

Las viejas estructuras nos aseguran a las mujeres un espacio social que conocemos y al que estamos acostumbradas a "sentirnos" seguras. Es cómodo escoger ese rol, no plantea riesgos y no exige decisión alguna para tomarlo. Públicamente hemos declarado la guerra a la sociedad de hombres, pero silenciosamente nos aprovechamos de las condiciones que nos ofrece. Nosotras utilizamos el Sistema como pretexto para no tener que vernos a nosotras mismas con realismo y para no tener que tomar el lugar de responsabilidad que nos corresponde para cambiar nuestra situación y nuestra historia (Mika, 2011, p. 20).

Se podrá o no estar de acuerdo con una posición tan extrema que atribuye a las mujeres "colaboración" en su situación discriminada. En todo caso es evidente que la ideología imperante de alguna manera tiene también que incidir en la forma en que las mujeres contemplan su propio lugar en la sociedad.

Tal vez eso explica cómo en la encuesta solicitada por Der Spiegel cuando se preguntó a las mujeres si asumirían gustosas una posición de dirección solamente el 25\% contestó que sí y el 75\% que no. Los hombres, en cambio, reaccionaron totalmente diferente a la misma pregunta: $43 \%$ respondió que sí y el $57 \%$ que no. Es miedo a asumir mayores responsabilidades es común a ambos sexos, pero mucho más fuerte entre las mujeres. 


\section{Rompiendo techos de vidrio con legislación afirmativa en Costa Rica}

En pocos países del mundo ha sido tan contundente, como en Costa Rica, el poder generador de cultura que tiene la legislación. Las acciones afirmativas a favor de los derechos de la mujer tienen origen, en Costa Rica, con el proyecto de ley "Igualdad Real de la Mujer", que se presentó al país, por primera vez, en el simbólico 8 de Marzo de 1988 y entró en la corriente legislativa un mes después.

La propuesta incluía una disposición muy genérica a la "... obligatoriedad de los partidos políticos para que durante las siguientes 5 elecciones, se presenten en las nóminas para puestos de elección un número de hombres y mujeres proporcional a los inscritos por cada sexo en padrón nacional electoral..." (Morales, 2007, p.5). En ese momento existía una oposición muy fuerte al proyecto. Desde la Iglesia, pasando por el Tribunal Supremo Electoral, los gremios empresariales, los sindicatos, los partidos políticos, varias organizaciones de mujeres, la izquierda tradicional y hasta legisladoras del partido de gobierno que había presentado la propuesta, objetaban sea roces con la constitución, sea el lugar legislativo para promover la igualdad política. Ningún criterio expresa mejor la oposición a esta ley que la expresada nada menos que por el Departamento de Servicios Técnicos de la Asamblea Legislativa quien estimó que era "inadecuado pensar que es mediante la promulgación de leyes que se puede alcanzar el propósito que este proyecto persigue" (Lozano, 1988, p. 6A).

Particularmente emblemático de esta oposición fue el criterio negativo expresado por la Comisión de Asuntos de la Mujer del Colegio de Abogados y el sector femenino de la Confederación Nacional de los Trabajadores. Objetaban el proyecto de ley las mismas mujeres diputadas del Partido Liberación Nacional, quienes finalmente lo apoyaron bajo fuerte, expresa y pública presión del precandidato de su partido. Pero aún entonces, las diputadas del partido de gobierno se mantuvieron bajo fuerte reserva, ya que -según reporta la prensa- declararon que "...es más importante que la discriminación quede relegada por un acto de conciencia del hombre" (Morales, 2007, p.8).

Cuando la ley fue finalmente aprobada, el 8 de Marzo de 1990, después de uno de los procesos de mercadeo político más profundos, extensos y exitosos de América Latina, no hacía una mención clara de "cuotas de participación de las mujeres". Lo que la ley mandaba en el campo político se había reducido a pedirle a los partidos que incluyeran en sus estatutos "... mecanismos eficaces que promuevan y aseguren la participación efectiva de la mujer en los procesos eleccionarios internos, en los órganos directores del partido y en las papeletas electorales" (Ley 7142).

Con todo y sus limitaciones finales, la nueva ley abrió un debate social que permitiría nuevos avances significativos. El camino fue lento y lleno de tropiezos. En la Asamblea Legislativa que aprobó la Ley de Promoción de la Igualdad de la Mujer había solamente 4 mujeres diputadas. En la siguiente legislatura (1990-1994), electa un mes antes de aprobarse la ley, el número de diputadas apenas aumentó a 6 y en la siguiente (1994-1996) a 9. Eso representaba un crecimiento homeopático del 4,38\% entre una elección y otra.

En 1994 se retoma la lucha por una cuota de mujeres en las papeletas electorales y se logra que en 1996 se apruebe una reforma al Código Electoral que menciona con claridad una cuota de $40 \%$ de mujeres en las candidaturas diputadiles. Aunque la propuesta original contenía la palabra "en puestos elegibles", la legislación aprobada suprimió esa precisión y tal vez por eso fue muy poco lo que la legislación logró en el fomento de la participación de mujeres en la Asamblea Legislativa. En 1996 resultaron electas apenas 2 diputadas más, un incremento proporcionalmente menor que en las elecciones anteriores. 
Fue entonces que, ante recursos planteados, el Tribunal Supremo de Elecciones interpretó, vía jurisprudencial, el sistema de cuotas de participación femenina implementado en nuestra legislación. Mediante su Resolución No. 1863 de 1999, reafirma por jurisprudencia, el principio de acciones afirmativas para avanzar hacia la equidad de género. Ahí el Tribunal afirma "la convicción de que la imposición de porcentajes de participación de las mujeres en el escenario político, constituye un medio compensatorio, que procura una concreción del derecho de igualdad de oportunidades". Es así que esta sentencia restituye la frase que había suprimido el legislador, en la propuesta de ley. El Tribunal expresamente dice: “... Estas consideraciones... conducen al Tribunal, en uso de su competencia interpretativa, a establecer que el porcentaje del 40\% de participación femenina en las papeletas diputadiles y municipales, tiene que darse necesariamente en puestos elegibles..." (Tribunal Supremo de Elecciones, Res. 1863, 1999).

Esta resolución tiene un fuerte impacto en la siguiente legislación, para la que son electas mujeres con un considerable incremento: casi el doble de mujeres diputadas que en la anterior, alcanzando el 35\% de mujeres diputadas. Eso lleva los principios de acción afirmativa a su hegemonía cultural, en todos los partidos.

Con una visión mucho más ambiciosa, la Ley No 8765, del 19 de agosto de 2009, crea el nuevo Código Electoral de Costa Rica, como "una de las legislaciones más modernas a nivel mundial para la efectiva participación política de las mujeres" (Hernández, 2010, p.1). El nuevo Código establece el principio de paridad (50\%) en los órganos internos y en las papeletas electorales, y también ratifica y mejora las resoluciones del Tribunal Supremo Electoral concernientes a la posición de las mujeres dentro de las papeletas electorales, al establecer el principio de alternancia según el cual, "todas las nóminas de elección popular y las nóminas a cargos en órganos de dirección y representación política estarán integradas en forma paritaria y alterna" (Ley 8765, art. 148). Para alcanzar su plena eficacia, este nuevo código establece sanciones a los partidos que no cumplan con sus disposiciones de paridad de género, entre otras, la eliminación de su inscripción en el Registro de Partidos y la anulación de candidaturas que fueran presentadas en violación del principio de paridad y alternabilidad.

Como era natural, un ambiente legislativo favorable a las acciones afirmativas, como el que se vive en la actualidad, llevaría en su dinámica a plantear también la extensión de las acciones afirmativas de lo político a lo económico, de las cuotas en las elecciones a las cuotas en las directivas de las organizaciones.

\section{El desafío de la competitividad por medio de la equidad de género en Costa Rica}

En Costa Rica, el planteamiento del tema de cuotas de mujeres en la dirección de las empresas tendrá como base las mismas condiciones que han obligado a dicho debate en el orden internacional: el contraste existente entre la cada vez mayor participación de mujeres en la fuerza de trabajo, con una proporción de mujeres con mayor escolaridad que los hombres, frente a condiciones de menores ingresos y menores oportunidades de acceso a puestos de dirección y de responsabilidad empresarial.

En los últimos 40 años, ha ido creciendo la proporción de mujeres económicamente activas. En 1970 estaban en el mercado laboral solo 2 de cada 10 mujeres, mientras que ahora casi 4 de cada 10 mujeres forma parte de la Población Económicamente Activa (PEA). "A pesar del alto crecimiento en su participación, la oferta laboral femenina constituye solo el 38\% de la oferta total" (Lexarta, 2010, p. 25), pero es un gran avance porque en 1990 las mujeres eran solamente el 28\% de la PEA y de la población ocupada. 


\section{FIGURA 2 \\ Relación entre profesionales en la PEA por sexo y directivos por sexo de profesionales en Costa Rica}

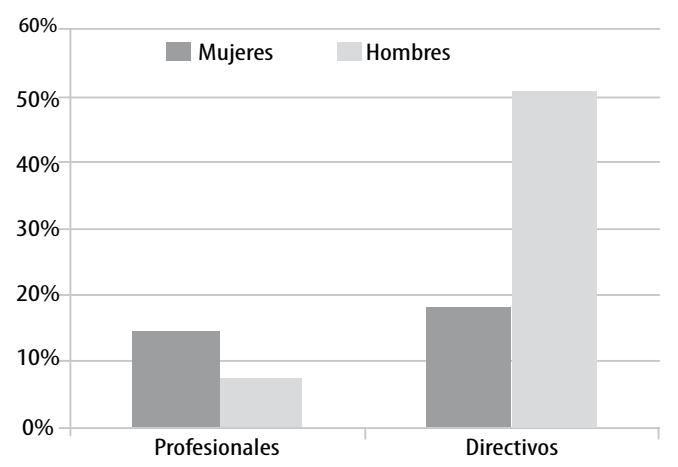

Fuente: Elaboración propia a partir de EHPM 2009 de INEC.

En Costa Rica, como parece ser la regla en casi todos los países del mundo, las mujeres que se insertan en el mercado de trabajo tienden a tener más educación formal que los hombres (Tabla 1). En 2009, los años de escolaridad promedio de las mujeres ocupadas alcanzaba los 9,9 años, mientras que los hombres tenían solo 8,5 años de educación formal. Como resultante actualmente el 50\% de las mujeres ocupadas tienen secundaria completa o más, contra un 33\% de los hombres con esos niveles de educación. De cada 100 profesionales, técnicos, científicos o intelectuales, 55 son mujeres y solo 45 son hombres. El 14,31\% de las 100 mujeres que trabajan son profesionales. En cambio, de cada 100 hombres en la PEA solo 7,12\% tienen ese nivel de calificación. Pero el mayor volumen absoluto y relativo de mujeres científicas o profesionales no significa que tengan acceso a puestos directivos en esa proporción. De cada 10 directivos 7 son hombres y solo 3 son mujeres (Ver Figura 2). Eso quiere decir que de cada 10 mujeres científicas o profesionales solo 2 alcanzan puestos directivos, mientras más de la mitad de los hombres científicos o profesionales, encuentra empleo a nivel superior jerárquico en las empresas (INEC, 2009).
Sin embargo, como también ocurre en otras partes, una mayor escolaridad tampoco ha significado para las mujeres ingresos similares a los hombres. Las mujeres ganan en promedio actualmente 25\% menos que los hombres. Esa brecha de ingresos en vez de disminuir ha ido creciendo. Curiosamente, a medida que se sube en la escala salarial, las brechas de ingreso por género son más grandes (Figura 3). Mientras en 2004 el ingreso de las mujeres era el 17\% menor que el de los hombres, en 2009 es ya $25 \%$ menos, en promedio.

FIGURA 3

\section{Brechas de Ingreso mensual según categoría ocupacional por género en Costa Rica}

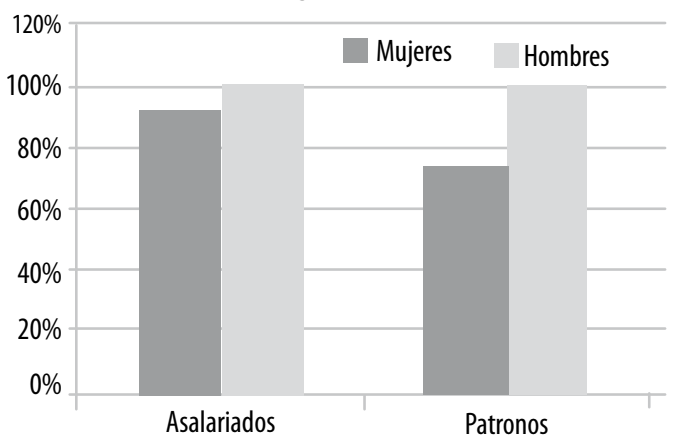

Fuente: Elaboración propia a partir de EHPM 2009 de INEC.

En Costa Rica, la Ley 8901 introdujo el tema de las cuotas de mujeres en la dirección de organizaciones civiles, pero se limitó a aquellas que no son productivas ni tienen fines de lucro. Su titulado es: "Porcentaje mínimo de mujeres que deben integrar las directivas de Asociaciones, Sindicatos y Asociaciones Solidaristas", y rige desde el 27 de Diciembre de 2010. Esa ley reforma la Ley de Asociaciones, la Ley del Trabajo y la Ley de Asociaciones Solidaristas, en el sentido de que "se deberá garantizar la representación paritaria de ambos sexos" en los organismos de dirección de estas organizaciones.

Esas "acciones afirmativas" acercan la legislación nacional costarricense a la discusión internacional de las cuotas de mujeres en la dirección de las empresas. Por el momento, la legislación costarricense limita su acometida afirmativa a organizaciones de carácter civil, no económico ni empresarial, ni siquiera en el caso, por ejemplo de las cooperativas. 
TABLA 1

\section{Costa Rica: Relación de género entre fuerza de trabajo, profesionales y directivos de empresas}

\begin{tabular}{|c|c|c|c|c|c|c|c|}
\hline & & Total & $\%$ & Hombres & $\%$ & Mujeres & $\%$ \\
\hline Fuerza de Trabajo & 1 & 2121451 & $100 \%$ & 1314981 & $62 \%$ & 806470 & $38 \%$ \\
\hline Profesionales, científicos o intelectuales & 2 & 209160 & $10 \%$ & 93697 & $45 \%$ & 115463 & $55 \%$ \\
\hline $\begin{array}{l}\% \text { de profesionales en PEA } \\
\text { por género }(C 2 / C 1) \text { y }(E 2 / E 1)\end{array}$ & 3 & & & & $7,1 \%$ & & $14,3 \%$ \\
\hline Nivel directivo en las empresas & 4 & 68698 & & 47816 & $70 \%$ & 20882 & $30 \%$ \\
\hline $\begin{array}{l}\text { \% de directivos por género } \\
\text { de profesionales (C4/C2) y (E4/E2) }\end{array}$ & 5 & & & & $51 \%$ & & $18 \%$ \\
\hline
\end{tabular}

Fuente: Elaboración propia a partir de EHPM 2009 de INEC.

A diferencia de la propuesta de Ley por la Igualdad Real, que inició en Costa Rica los procesos de acciones afirmativas a favor de las cuotas de mujeres, en el caso de la Ley 8901, que pasó con poca controversia, la polémica surgió después, como reacción a una legislación que no tomó en cuenta realidades específicas culturales, sociológicas o de asociaciones y sindicatos en Costa Rica. Así, por ejemplo, las juntas directivas de patronatos escolares han tenido tradicionalmente una abrumadora mayoría femenina. La conformación de la paridad aparece difícil de lograr cuando hay muy pocos hombres postulándose a esos cargos y, sin la paridad, no son legales sus juntas directivas y crea el peligro de que los patronatos escolares queden suspendidos. La Ley ha provocado ya dos acciones de inconstitucionalidad y un recurso de amparo. El Sindicato Independiente de Trabajadores Estatales Costarricenses (SITECO) denunció la situación que enfrentan los Cen-Cinai, donde 24 juntas directivas fueron rechazadas por la Dirección Nacional de Desarrollo de la Comunidad (DINADECO), al carecer de suficientes integrantes varones. Esto es tanto o más grave que el caso de los patronatos escolares, ya que sin personería jurídica, no pueden los Cen-Cinai acceder a los recursos económicos que el Ministerio de Salud extiende para el mantenimiento de los centros y la alimentación de los niños (Ross, 2011). En esta situación se encuentran potencialmente 650 asociaciones de Cen-Cinai.

Álvaro Sáenz, de la Asociación Cámara Nacional de Agricultura y Agroindustria, planteó una acción de inconstitucionalidad alegando que existen decenas de grupos de mujeres campesinas que ya no podrían operar, de acuerdo con esa ley. En marzo, Gilberth Brown Young, del Sindicato de Trabajadores Petroleros Químicos y Afines, presentó otra acción de inconstitucionalidad por la reforma que alude a los sindicatos.

Otra situación que debió ser tenida en cuenta, fue la de las asociaciones de desarrollo de los territorios indígenas, que fungen como gobierno local y tienen fuertes tradiciones de dirección masculina que no se pueden violentar sin un proceso gradual de adaptación cultural.

Todas estas situaciones crean el peligro de reacciones negativas y la ley posiblemente tenga efectos no esperados de rebote en el campo de futuras acciones afirmativas.

Ese tropiezo momentáneo no cambia las razones de fondo para las acciones afirmativas en el 
campo empresarial. Esas consisten en la constante desproporción entre la mayor capacidad laboral de las mujeres y sus ingresos, entre su mayor nivel académico y sus limitadas responsabilidades en la vida económica. De ahí que también en Costa Rica se sigue planteando con las cuotas de mujeres en las direcciones de las empresas, no solamente un problema de equidad sino también de subutilización de las capacidades plenas del país para aumentar su propia competitividad.

Las brechas salariales y de oportunidades de superación laboral existentes apuntan a la pervivencia del viejo razonamiento económico de los fundadores del pensamiento económico liberal, cuya lógica persistente ha siempre basado la participación laboral de las mujeres en el menor valor de la fuerza femenina de trabajo. Mientras existan esas brechas de salarios y de responsabilidades, se puede seguir considerando que las empresas "ahorran" considerablemente con el empleo de la fuerza de trabajo femenina. Evidentemente la competitividad por la vía de mayores rendimientos, innovación tecnológica y visión empresarial tiene mayor dinamismo que la competitividad por vía de menores costos. El problema que se plantea es precisamente ese: el de encontrar los mejores instrumentos para que la incorporación de las mujeres a la producción y a la administración de las empresas supere la lógica todavía existente de racionalización de costos vía menores salarios, y enfrente, con mayor determinación, el más significativo, humanamente dignificante y económicamente racional objetivo de alcanzar la optimización competitiva por mejores rendimientos.

\section{CONCLUSIÓN: DE LA EQUIDAD A LA COMPETITIVIDAD}

Queda expresada la contradicción existente entre la proporción de mujeres con alta calidad educativa, calificación profesional y desempeño corporativo y su débil acceso a los puestos de dirección de las empresas. Ese contraste parecería ir contra toda racionalidad económica y eficiencia competitiva. Los obstáculos invisibles que tienen las mujeres para alcanzar representación en puestos directivos significa, más que una limitación al progreso de las mujeres en la vida social, una limitación que se autoimponen los países del mundo cuando renuncian a la plena utilización del segmento más calificado y de menor costo de su fuerza productiva. Esta exposición ha tratado de subrayar las lógicas económicas competitivas que han estado detrás de la incorporación de las mujeres a la fuerza de trabajo, así como señalar la manera en que esa lógica de utilización de la mano de obra femenina no funciona cuando se trata de colocarlas en centros de liderazgo. En respuesta a esa contradicción sectores liberales, incluso de la derecha política, han avanzado legislación positiva de cuotas obligatorias de mujeres en la administración de las empresas, en países tan emblemáticos y desde tan amplios espectros políticos como Noruega, Francia y España y el tema se debate con algidez en Alemania. Costa Rica no es ajena a esta polémica, como lo ejemplifica la reciente y mencionada supra Ley 8901 y todas las contradicciones que ha suscitado.

No es argumento de esta exposición asumir la defensa del sistema de cuotas para resolver estos contrastes. Los formidables avances educativos y el eficiente desempeño corporativo demostrado por mujeres líderes de empresa muestran un potencial social subutilizado de competitividad. La ruta humana del progreso coloca el avance de las mujeres más allá de su carácter básico de equidad y pone en la agenda de las naciones la plena incorporación del liderazgo de las mujeres para beneficio competitivo de las sociedades. Ese es el tema de debate actual, dentro del cual las cuotas son uno de los mecanismos que se discuten, hoy en día, como herramientas para enfrentarlo. 


\section{REFERENCIAS}

Adams, A. y Adams, J. (2002). Selected Letters of the Adams Family, 1762-1784. Boston, Massachusetts: Northeastern University Press.

Asamblea Legislativa. Ley n. 7142 Ley de promoción de la igualdad social de la mujer. San José: La Gaceta n. ${ }^{\circ} 59$ del 26 de marzo de 1990. Recuperado el 28-04-2011 de: http://www.iidh.ed.cr/BibliotecaWeb/Varios/ Documentos/BD_819498281/Legislacionigualdad/ costa\%20rica.pdf.

Asamblea Legislativa. Ley $n .^{\circ} 8765$ Código Electoral de Costa Rica. Recuperado el 28-04 de 2011 en: http:// www.asamblea.go.cr/Centro_de_informacion/Centro _Dudas/Lists/Formule\%20su\%20pregunta/ Attachments/296/8765\%20codigo.pdf.

Barbieri, T. (2002). Memorias del Foro Mujeres y Política. México: Instituto Nacional de las Mujeres. Recuperado el 23-042011 de: http://www.ife.org.mx/docs/IFE-v2/DECEYEC/ DECEYEC-IFEMujeres/Mujeres-SitiosTemasInteres/ Mujeres-Sitios-estaticos/Perspectiva_genero/ Memoria_foromujeresypol.pdf

Beyer, S. y Voigt, C. (2011). Die Machtfrage. Der Spiegel, 5/11.

Borloz, V. (2001). Madame Bovary soy yo: Flaubert y la literatura costarricense. San José: EUNED.

Calvera, L. (1982) El género mujer. Buenos Aires: Editorial Belgrano.

Catalyst. (2011). The Bottom Line: Connecting Corporate Performance and Gender Diversity. Recuperado el 2204-2011 de: http://www.catalyst.org/file/44/the\%20 bottom\%20line\%20connecting\%20corporate\%20 performance\%20and\%20gender\%20diversity.pdf.

Condorcet, N. (1790). Sur l'admission des femmes au droit de cité. Journal de la Société de 1789, n. ${ }^{\circ}$. Edición electrónica. Recuperado el 10 de Abril de 2011: http:// classiques.uqac.ca/classiques/condorcet/admission_ femmes_droit_de_cite/condorcet_droit_de_cite_ des_femmes.pdf

Cotter, D., Hermsen. J., Ovadia, S. y Vanneman, R. (2001): The Glass Ceiling Effect. Social Forces. 80(2): 655-682.

Dahlerup, D. (2005). No Quota Fever in Europe? Budapest: Institute for Democracy and Electoral Assistance (IDEA).

Diálogo Inter-Americano/Gallup. (2000). Latinoamericanas en el mando. Una encuesta a la opinión pública. Com- pendio ejecutivo recuperado el 6-04-2011 de: http:// www.thedialogue.org/Gallupsummary_spanish.htm

Duby, G. y Perrot, M. (2001). Historia de las mujeres en Occidente, vol. IV. Madrid: Taurus.

Fauré, C. (2010). Enciclopedia Histórica y Política de Las Mujeres. Madrid: Akal.

Fischer, S. (2011, 02 de febrero). Frauen müssen sich trauen. Spiegel Online. Recuperado el 2304-2011 de: http://www.spiegel.de/politik/ deutschland/0,1518,743091,00.html

Govaere, V. (2011, 6 de marzo). Hacia arriba y empedrado. La Nación. Costa Rica. Recuperado el 12-04-2011, de: http://www.nacion.com/2011-03-06/Opinion/Foro/ Opinion2704417.aspx

Hausmann, R., Tyson, L. y Zahidi, S. (2009). Global Gender Gap Report 2009. Suiza: World Economic Forum. Recuperado el 15-04-2011 de: https://members. weforum.org/pdf/gendergap/report2009.pdf

Hernández, H. (2010). Aprobación del nuevo Código Electoral: Por una real participación política de las mujeres en Costa Rica. X Congreso Centroamericano de Historia UNAN-Managua. Recuperado el 28-04-2011 de http:// hcentroamerica.fcs.ucr.ac.cr/Contenidos/hca/cong/ mesas/x_congreso/genero/celectoral-costarica.pdf.

Holmes, S. (2008). Smashing the Glass Ceiling. BBC News. Recuperado el 19-04-2011 de: http://news.bbc.co.uk/2/ hi/7176879.stm.

Instituto Nacional de las Mujeres (INAMU). (2011). Sistemas de Indicadores estadísticos de género. Recuperado el 28-04-2011 de: http://www.inamu.go.cr/index. php?option=com_content\&view $=$ article\&id $=422 \&$ lte mid $=378$

Instituto Nacional de Estadística y Censo (INEC). (2009). Encuesta Nacional de Hogares de Múltiples Propósitos 2009. Empleo. Costa Rica. Recuperado el 30-04-2011 de: http://www.inec.go.cr/Web/Home/ GeneradorPagina.aspx

Kennedy, J. F. (1961). Executive Order 10925. Recuperado el 15-04-2011 de: http://www.presidency.ucsb.edu/ws/ index.php?pid=58863\#axzz1 Im8qwOk4

Lexartza, L. (2010). Transformaciones en el mercado laboral y en los hogares costarricenses en los últimos 20 años. Trabajo decente y corresponsabilidad social en el cuido. Retos en el camino hacia la igualdad. San José: Organización Internacional del Trabajo. 
Llanos, B. y Sample, K. (2008). 30 años de democracia ¿en la cresta de la ola? Participación política de la mujer en América Latina. Estocolmo: International Institute for Democracy and Electoral Assistance (IDEA).

Lozano, R. (1988,16 de junio).T.S.E. objeta reforma al Código Electoral. Proyecto de igualdad de la mujer. La Nación, p. $6 \mathrm{~A}$.

McKinsey \& Co. (2008). Deutschland 2020 - Zukunftsperspektiven für die deutsche Wirtschaft. Recuperado el 12-042011 de: http://www.mckinsey.de/downloads/profil/ initiativen/d2020/D2020_Exec_Summary.pdf

Michler, I. (2011, 06 de Febrero). Die Angst vor der Quote sorgt endlich für Bewegung. WELT AM SONNTAG. Recuperado el 23-04-2011 de: http://www.welt.de/ print/wams/vermischtes/article12460699/Die-Angstvor-der-Quote-sorgt-endlich-fuer-Bewegung.html

Mill, S. (2010). El sometimiento de la mujer (1869). Madrid: Alianza Editorial.

Morales, C. (2007). Ley de promoción de la igualdad social de la mujer: Un ejemplo de compromiso político y articulación social. San José: Instituto Interamericano de Derechos Humanos.

Organización Internacional del Trabajo (OIT). (2009). Informe mundial sobre salarios. Recuperado el 10-04-2011 de: http://www.lo.org/wcmsp5/groups/public/@ dgreports/@dcomm/documents/publication/ wcms_116502.pdf

Peschard, J. (2002). El Sistema de Cuotas en América Latina. Panorama General. Suecia: Institute for Democracy and Electoral Assistance (IDEA).

Ramos, M. (2005) Mujeres y liderazgo. Una nueva forma de dirigir. Valencia. Universitat de València.
Ross, A. (2011, 29 de Marzo). Ley de cuota femenina entraba a sindicatos y asociaciones. La Nación. Recuperado el 1-04-2011 de: http://www. nacion.com/MensajesGenericos/PageNotFound. aspx?aspxerrorpath=/2011-03-29/ElPais/ NotasSecundarias/EIPais2729793.aspx

Say, J. (1803). Traite de'l economie politique. Libro Digital recuperado el 12-4-2011 de: http://classiques.uqac. ca/classiques/say_jean_baptiste/traite_eco_pol/ traite_eco_pol.html

Scott, J. (2001). La mujer trabajadora en el siglo xix. P. 8. Recuperado el 13-4-2011 de: http://www.fhuc. unl.edu.ar/olimphistoria/paginas/manual_2009/ docentes/modulo1/texto3.pdf

Seith, A. (2010, 17 de Setiembre). Eu-Plan für Frauenquote spaltet Schwarz-Gelb. Spiegel-Online. Recuperado el 14-04-2011 de: http://www.spiegel.de/wirtschaft/soziales/0,1518,718087,00.html

Smith, A. (1976). An Inquiry into the Nature and Causes of The Wealth of Nations (Facsimil de la edición de1776). Chicago: University of Chicago Press.

Suplecy, M. (1996). Novos paradigmas nas esferas de poder. Estudos Feministas, 4 (1), p. 131.

Visser, M y Gigante, A. (2007). Women on Boards - Moving Mountains.Women@Work (8/2007). Recuperado el 17-4-2011 de: http://www.europeanpwn.net/index. php?article_id $=54$

Wollstonecraft, M. (2008). A Vindication of the Rights of Women (1792). New York: Cosimo Inc.

Recibido: 15-05-2011

Aceptado: 23-09-2011 